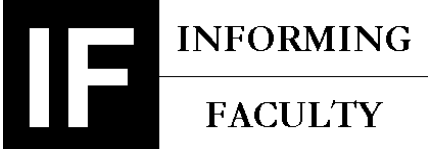

2014-02-1

MARCH 1, 2014

GRANDON GILL, AMY J. CONNOLLY

\section{PLAGIARISM AND THE CLASS PROJECT}

"Just a week ago, things had been going so well..." Grandon Gill thought to himself as he considered the situation that was rapidly turning his MS-MIS capstone course at the University of South Florida (USF) into a train wreck.

Just nine weeks before, in late August 2013, Gill had challenged his students with a new class activity. The purpose of the activity was to take a debate research assignment that he had been using for nearly a decade to the next level. In addition to presenting the debate in class, the students would be taking the research that they conducted in preparing for the debate and transforming it into book chapters. The ultimate objective: to attain a level of quality that would justify publication of the book under the auspices of the Informing Science Press. To achieve this ambitious goal, Gill had instituted a systematic peer review process. In addition to presenting or writing part of a chapter, each group would be responsible for reviewing the work of other students and providing constructive feedback.

Through the end of October, the process appeared to be working more or less according to plan. Chapters were being delivered more-or-less on time and student reviews were being submitted, although somewhat less detailed than Gill had originally hoped. Since it seemed as if the publication objective might be attainable - and the students reported being enthusiastic about the process - he brought in an MIS doctoral student, Amy Connolly, to assist in the editing and formatting of the book for publication that would take place in mid-November. Shortly after Connolly began work, she contacted Gill with a concern. $75 \%$ of the content of one of the early chapters of the book appeared to be copied from a variety of sources without attribution. In other words, it had been plagiarized.

Given the number of times he had warned students about the implications of plagiarism, Gill was shocked to discover such a blatant example. He immediately arranged a meeting with the students, his department chair and the director of the department's graduate programs. After about an hour's worth of discussion, it was agreed that the students would suffer a serious penalty in their course grades, consistent with

\footnotetext{
This case was prepared for the purpose of class discussion, and not to illustrate the effective or ineffective handling of an administrative or classroom situation and is copyrighted by the Informing Science Institute. Permission to make digital or paper copy of part or all of these works for personal or classroom use is granted without fee provided that the copies are not made or distributed for profit or commercial advantage AND that copies 1) bear this notice in full and 2) give the full citation on the first page. It is permissible to abstract these works so long as credit is given. To copy in all other cases or to republish or to post on a server or to redistribute to lists requires specific permission and payment of a fee. Contact Publisher@InformingScience.org to request redistribution permission.
} institutional policy.

Unfortunately, however, he was uncomfortably aware of the fact that this decision would not be the end of the matter. Just before the meeting, he had been approached by Connolly who had reported:

"We have problems with some of the other chapters..." 


\section{Plagiarism}

In simple terms, plagiarism is taking credit for someone else's work (Merriam Webster dictionary). First, presenting someone else's ideas as your own, and second, not giving credit to the source ("Plagiarize," 2013). In the U.S., teachers inherently assume that students should only turn in their own original work. However, with a plethora of readily available online information sources, it is inevitable that students will copy something, whether intentionally or unintentionally.

Plagiarism includes a range of activities, from blatant and direct copying of passages to rewriting someone else's ideas in your own words without attribution, also sometimes known as "patch-writing." (USF Library, 2013) First time writers often plagiarize unwittingly. Even though the student researched the ideas and organized them himself, by using another's words without attribution, it is still plagiarism. (USF Library, 2013) Borrowing a passage, changing the first and last sentences, and creating a coherent whole does not change the fact that the end product is not the student's own thoughts and ideas (USF Library, 2013).

While it is not plagiarism to quote a substantial portion of a published work (so long as the source is identified), it may be copyright infringement. Although they are related and may happen simultaneously, plagiarism and copyright infringement are not the same thing. Copyright protects authors and publishers from losing money for their work. Authors and publishers have the right to sell and lease copyrights to allow others to reproduce their work. Copyright infringement reduces the publisher's profits, but it is not plagiarism.

SV-POW Blog gives four examples to distinguish between plagiarism and copyright infringement. In essence, not attributing the author's ideas is plagiarism, but not getting permission to publish large amounts of another's published work is copyright infringement.

The U.S. Copyright Office (n.d.) defines copyright violation as taking someone else's copyrighted work and reproducing, distributing, performing, publicly displaying, or making into a derivative work without permission. "A copyright protects works of authorship, such as writings, music, and works of art that have been tangibly expressed" (US Patent \& Trademark Office, n.d.). US Legal Code lists a multi-prong standard to determine whether an author has crossed the line from fair use quoting to blatant copyright infringement. The Patent Office states:

Under the fair use doctrine of the U.S. copyright statute, it is permissible to use limited portions of a work including quotes, for purposes such as commentary, criticism, news reporting, and scholarly reports. There are no legal rules permitting the use of a specific number of words, a certain number of musical notes, or percentage of a work. Whether a particular use qualifies as fair use depends on all the circumstances. See FL 102, Fair Use, and Circular 21, Reproductions of Copyrighted Works by Educators and Librarians.

In education, when plagiarism is detected, penalties can be severe. As a student, penalties vary based on the severity of the offense and the circumstances. It is usually up to an instructor's discretion whether to escalate the issue and potentially destroy a student's academic career. This decision is rarely taken lightly. Punishments range from a simple warning all the way up to expulsion and academic censure. (USF policy, see Exhibit 1).

Publishers who infringe copyright or plagiarize published works can be sued for damages and lose their reputation as a reputable source. Although such cases may sometimes be hard to pursue, they are a black 
mark on a publisher's record. Plagiarism and copyright infringement are considered a form of intellectual theft.

Although researchers and students may not realize it, academic journals sell subscriptions to libraries and schools. If they publish copyrighted and/or plagiarized works, then, as publishers, they are at risk for litigation. Reviewers are supposed to catch these problems before they occur, but it's not always easy. No one can possibly read the millions of articles published every year in every journal. Therefore, not every case of plagiarism or copyright infringement is caught. A journal that allows plagiarism may lose its reputation as an authoritative source in its field, and thus, lose its paid subscribers.

Spotting plagiarism is easier for a reader familiar with the writer's style, but automated tools are available to find plagiarism and to check that sources are properly cited for quoted material. In fact, some of these software keep an extensive database of previous student papers (in addition to formal published works) to catch students who resubmit old assignments. Because not all instructors change assignments from one semester to the next, these software tools attempt to catch cheating by comparing new work to old work.

Self-plagiarism is another issue. In self-plagiarism, an author does not properly cite his own work. Since it is technically his own ideas, the student owns the rights to his own work. However, academic policies state that students shall not receive double credit for the same work in two separate classes or assignments (without instructor's approval). In academia, there is some debate whether self-citation is necessary or is in fact blatant self-promotion. The number of citations of a work increases the article's impact factor. Impact factor is used in tenure and promotion decisions and is sometimes more important than number of publications. Although self-citing artificially inflates an author's impact factor, it avoids the ethical dilemma of self-plagiarism.

One well known plagiarism detection tool (and the one used in this case) is called TurnItIn. TurnItIn is free for instructors and commonly built into learning management systems for ease of use. TurnItIn checks against officially and unofficially published works online, including other student papers. The software gives the instructor and student a report of the percentage of material copied from other sources on any given assignment. Students can pay a small fee to check their assignment before submitting it. The fee is to reduce the likelihood that students will "game" the system. Other examples of automated tools include Plagiarism Checker, SPlat, TinEye, and Plagiarism Detect (Nabi, 2012). SPlat checks for selfplagiarism and TinEye evaluates pictures and figures for reuse.

\section{The Course}

The course in which the incident occurred was Enterprise Information Systems, the capstone course in the MS-MIS program. As a capstone, the course's objective is for students to integrate the knowledge acquired throughout the 30-credit graduate program. As stated in the syllabus, the learning objectives of the course were as follows:

To ensure students leave the MS-MIS program with:

1. An appreciation of the complex interaction between individual and organizational forces and technological issues in the development, deployment and use of information systems, with a particular focus on organizational strategy

2. An understanding of how events in the evolution of MIS have impacted its current form in organizations

3. The ability to articulate convincing positions with respect to some of the most critical debates in the field of IT today 
4. Familiarity with some of the types of activities that constitute MIS research

The course lasted 12 weeks, meeting once a week at night. Traditionally, the time during these four hour night sessions was built around two core classroom activities:

- Case discussions: Each week in class, the students would discuss a case study related to information systems in organizations. Most of these case studies were acquired from Harvard Business School publishing, with 2 to 3 additional cases developed by the instructor.

- Debates: Starting about the fourth week of class, students would participate in debates on specific IT-related topics. Students were allowed to choose the topics they debated. Students selected topics during the first week of class. The student's assigned position (pro or con) was then determined randomly by the instructor using a spreadsheet. Exhibit 2 contains an outline of the debate instructions and topics from the course syllabus.

Normally, enrollment in the course was in the range of 20 to 30 students. That allowed students to be assigned to 2 to 3 debate teams apiece without the team size becoming unmanageable (e.g., more than 3 people per side, plus a moderator). Over the course of the semester, it also allowed ample opportunities for students to participate in the 11 case discussions that occurred in class-representing roughly $50 \%$ of their grade. On the rare occasions when the class size grew to over 30, Gill normally added an outside activity to supplement the cases and debates.

In mid-August 2013, Gill was alarmed to discover that 60 students had signed up for his class - nearly double the previous maximum. Essentially, this increase was a consequence of the dramatic jump in the number of international students from India, a trend experienced nationally in the U.S. in 2013 (Korn, 2013). A class of this size required a radical rethinking of the course activities. Even with 8 debates, requiring just one debate per student would result in pro or con team sizes of 3 or 4 , the practical maximum. This challenge led to the instruction of the book writing activity.

\section{The Book Writing Activity}

The objective of the book writing activity was to take students' research from preparing for debates and turn it into chapters of a book that would eventually be published as a collection of debates. Each chapter would be organized into three sections:

1. Body: The main section of the chapter, it would lay out the issues, facts and technologies related to the debate topic without taking sides.

2. Pro: Prepared by the team responsible for arguing in favor of the debate resolution, it would summarize the arguments made in their classroom presentation, drawing upon outside references and the material in the chapter body.

3. Con: Prepared by the team responsible for arguing against the debate resolution, it would summarize the arguments made in their classroom presentation, again drawing upon outside references and the material in the chapter body.

Peer review was an integral part of the book writing activity. Indeed, the entire activity's inspiration largely resulted from an email Gill had received from a faculty developer of Expertiza, a course-oriented peer-review software application. Expertiza was undergoing development and testing at North Carolina State University. Gill immediately recognized that such an application could be used to organize an activity around the debates that involved creating papers or chapters based upon the debate topics.

With this thought in mind, Gill contacted Eli Cohen and Betty Boyd, the publishers of the Informing Science Press posing a simple question: would the organization be willing to consider publishing a 
student-developed book on IT debates of current interest? Cohen and Boyd responded affirmatively provided - of course - that the quality was high and that Gill (who had previously published a number of books with the IS Press) took responsibility for the formatting and quality control of the manuscript. Ever the optimist, Gill immediately decided that creating a publishable work should be the objective of the project.

Recognizing the threat that plagiarism posed to the activity, Gill made numerous references to its seriousness in class. He explained that plagiarism was the one thing that could derail the project. Gill's face-to-face approach in alerting the class was taken specifically to ensure that they were made aware of the strength of his beliefs. He felt this necessary because plagiarism was too often a boiler-plate item on a syllabus, that it was not enforced, or that it was addressed with a mere warning. The nature of the book project - targeting a published work - meant that its potential consequences were far more severe.

\section{Process}

In order to manage the process of developing the book, student teams were assigned specific roles in the writing and reviewing process. As described in the syllabus (see Exhibit 3), four teams worked on a particular chapter. Each student performed all four roles but on different debates.

- Briefing team: Prepared a presentation on the debate topic a week before the debate and was responsible for peer reviewing the body of the chapter. Half the class was divided up into briefing teams to cover the seven debates.

- Chapter team: Responsible for writing the chapter body (hopefully building upon material presented in the briefing) and for reviewing the Pro and Con sections of the completed chapter. The remaining half of the class was divided into chapter teams to cover the seven debates.

- Pro and Con debate teams: Responsible for adding Pro and Con sections to the end of the chapter related to their debate. All members of the class were assigned to a debate team (which could not be the same topic as their briefing or chapter assignment).

The plan for assembling a particular chapter involved a 4 week sequence, as follows:

- Week 0: Debate briefing takes place in class

- Week 1: Pro and Con teams conduct debate in class

- Week 2: Chapter body is submitted

- Week 3: Chapter reviews completed, Pro and Con teams add their sections to the chapter

- Week 4: Chapter team completes reviews of Pro and Con sections and chapter is ready for final quality control.

Because the 12-week semester did not provide sufficient time for the final chapter to be completed according to this schedule, no class was scheduled in the week prior to the final class period, allowing more time for the teams assigned to that chapter.

\section{Document and Review Management}

During the first week of class, Gill worked with the faculty developer of Expertiza to develop a peerreview template. At that point, he realized that the application did not support the actual creation and management of the document being reviewed. To address this need, he created a shared folder on the cloud-based Google Docs site and developed templates for chapters. The site is shown as Exhibit 4 and a portion of the Master Chapter Template is included as Exhibit 5. 
Ever distrustful of being over-dependent on a software application — particularly one where faculty developers were involved - Gill used the Google Site to create a backup location for student peer reviews, and also provided a Master Review Template (Exhibit 6) that provided the same questions as the Expertiza site.

\section{Early Implementation Issues}

Early in the course, a number of issues arose that required minor changes to the course design. First, during the first class Gill pointed out that the capstone course was supposed to be taken at the end of the program, not the beginning. That announcement immediately caused 22 of the 60 students to drop out, which disrupted the teams that were starting to form and resulted in a shortage of students for some tasks. One chapter team in particular found itself with only one member. As a key consequence, the workload associated with the chapter activity effectively increased.

In the third week of class, after one evening's session, over a dozen students from the class attended a birthday party at a local apartment complex where many resided. In the course of that party, an armed intruder entered and held them hostage for over an hour. He then left, killing himself later that evening. This traumatic event led the class to request an earlier ending time for future sessions. Gill accommodated this request by turning the debate briefing into an online activity, which effectively eliminated the planned Q\&A session that was supposed to follow the briefing.

Finally, to address the confusion caused by having two parallel reviewing systems, Gill decided to make Google Docs the principal system, with subsequent posting of reviews to Expertiza optional.

Beyond these relatively minor modifications to the course plan, through the end of October, the course and book project appeared to be proceeding more-or-less as planned. The only exception was that Gill had relaxed the deadlines on chapter and review submissions in light of the above-mentioned events and changes to the review procedures. As a to-be-expected consequence, chapters and reviews were being submitted somewhat later than planned.

\section{Initial Detection and Response}

In the last week of October, Gill skimmed the first five chapters that had been submitted to date, as well as the student reviews. Based upon that reading, he concluded that publication was still feasible, but that the pace of work needed to be increased and further support was needed. Towards that end, he took two direct actions:

1. He encouraged Amy Connolly, a fifth year doctoral student, to join the project. In return for her effort, she would share editorial credit on the book and would participate in co-authoring a paper that Gill anticipated would be written to describe the activity and assess its learning impact.

2. He announced a moratorium on late penalties for reviews and chapter completions submitted by 31 October 2013 (the second to last class meeting).

The latter of these had the desired effect of producing a burst of activity from the students and, by the end of October, nearly all missing items had been submitted to the Google Docs site. At that point, Connolly began her initial review of the early chapters, intending to add her suggestions to the chapter authors to those already made by their classmates and Gill.

\section{Detection}

During her review of the second chapter, a number of phrases in the body of the chapter - such as ones referring to the authors' prior work-sparked Connolly's concern. She began to "Google" selected 
phrases in quotes, confirming her fears. On 3 November 2013, she sent the following email to Gill (brackets used to redact identifying information):

It looks like a large part of [a chapter] is plagiarized. I found two of the sources. They are directly copy/pasted, not even paraphrased. I had made my own edits about one-third through it before I realized that it was not an original work. I have not read the pro/con sides yet. Can you take a look and tell me how to proceed on [that chapter]? I will move on to [the next chapter].

Subsequent investigation, including submitting the work to TurnItIn.com through the university's Canvas learning management system, led Connolly and Gill to conclude that roughly $75 \%$ of the chapter body had been directly copied from the identified sources. Neither had ever encountered a more blatant example of plagiarism.

\section{Response}

Upon recognizing the severity of the problem, Gill immediately emailed the students involved and requested a meeting (Sunday, 3 November 2013). He then sent another email to his department chair (Exhibit 7), and requested that he be available to meet with the students involved. The chair agreed and further suggested that the faculty director of the department's graduate programs be included in the meeting.

The next day, Monday, 4 November 2013, Gill met with the chair and director to outline the rationale for the action that he proposed in his email (Exhibit 7). There were three aspects to it:

1. A grade of $\mathrm{C}$ was the minimum grade that could be assigned without requiring the students to repeat the entire course and, potentially, threaten their continued enrollment in the program. Since all three students were international students on student visas, disenrollment — even temporarycould threaten their ability to remain in the U.S.

2. By requiring the students to review the remaining chapters for plagiarism, Gill sought to reinforce the lesson on the seriousness of the offense (in case the low grade was not enough). It would also increase the likelihood that hidden plagiarism in the remaining chapters would be detected.

3. By requiring the students to compose an email describing what had happened and apologizing to their classmates, the message would be further reinforced - and the fact that Gill had already decided to postpone or cancel publication of the promised book in light of the incident would be explained. A great part of Gill's true motivation for requiring such an apology, however, was to motivate the remaining students in the class to remedy any plagiarism quickly, i.e., before it was "officially" detected therefore needing to be punished.

The chair and director immediately agreed to the first two elements of the plan. They expressed some concerns, however, about the privacy implications of the third item. Gill's argument consisted of the fact that the book project was, in fact, a single class project - not a set of seven individual chapter projectsand that everyone in the class needed to be informed as to why it was being derailed (at least as far as the current semester was concerned). He further argued that it would be kinder to let the students send the email themselves - allowing them to explain what they did in their own words - than to have the email come from the instructor. The chair and director eventually agreed to the entire plan, subject to the outcome of the actual meeting.

The meeting with the chapter authors was scheduled for 2:30 PM on Tuesday, 5 November, two days after the emails were sent. As Gill was about to enter the meeting room, Connolly stopped him in the corridor, saying: 
"There are significant problems with another chapter."

\section{The Meeting}

The meeting followed a sequence that the panel (i.e., Gill, the chair and the director) had agreed to in advance:

1. Gill briefly outlined Connolly's findings, and explained their seriousness.

2. The students were allowed to explain what they did without interruption.

3. The panel posed questions to the students.

4. The possible consequences were discussed, including the relevant university policies.

5. The panel met briefly to confirm a course of action.

6. The students were informed.

During the meeting, the students offered three justifications for their actions:

1. They had not wanted the chapter draft to be late since that would have interfered with the peer review process and, therefore, had felt pressured to get something up.

2. They had never intended to allow the plagiarized content to stand; it had merely been a placeholder for the content that they intended to write. As further proof, they noted that they had submitted a completely rewritten chapter just that morning.

3. They had assumed that since revisions were to take place until the end of the semester, and grades would not be assigned until then, their submission was not "official" until that point in time.

During the third phase, the panel pointed out several inconsistencies in these explanations. Most importantly, it made no sense to put a document out for review by student peers knowing full well that the final result would not resemble the original submission. In fact, their classmates were effectively wasting their time in reviewing the work of other authors. In addition, given that each chapter had an assigned due date, it seemed a stretch to imagine what was placed on Google Docs for others to review was not, in fact, "submitted".

In phase 4, as well as phase 1, Gill reiterated the potential career-destroying collateral damage that such plagiarism could have caused had it had gone undetected, given the objectives of the book project. Although he was a tenured professor, and could have probably weathered the storm suffering only major embarrassment for his role as co-editor of the work, the same could not be said for Connolly-who was planning an academic career that could have been completely derailed if plagiarism had been detected during the early years while she was attempting to earn tenure. In phase 5 , the panel privately concluded that Gill's original disciplinary actions were supported by what they had heard in the meeting.

Clearly shocked by their severity, the students nevertheless agreed to abide by the three elements of the disciplinary action - the maximum grade of $\mathrm{C}$, the requirement that they search out other plagiarism, and that they compose an email in their own words explaining what had happened to their classmates. That email, sent out 2 days later, is included as Exhibit 8.

\section{Current Situation}

A week after the original student group sent out its email — on the last day of class, the official end of the 12 week semester-Gill used TurnItIn to conduct an "official" check of the seven chapters. The results were as follows: 
- Two chapters - including the rewritten chapter of the original group - were free of any detectable text plagiarism.

- Four chapters included serious plagiarism violations - usually in the form of lengthy sentences or blocks of text copied from websites.

- One chapter explicitly block quoted roughly $80 \%$ of its content. While this avoided plagiarism, it left the chapter open to concerns of copyright violation.

In addition, while nearly all the figures in all of the chapters had included adequate citations, many appeared to come from sources where explicit permissions would be required prior to publicationsomething students had been warned to avoid.

These somewhat dispiriting findings were similar to those of an "unofficial" check that Gill had run a week before, just after the first group of students had sent out their email to classmates (i.e., Exhibit 8). By making that first check "unofficial", he had hoped that the warning email would lead to corrections of the type that had been made on the first original plagiarized chapter to avoid "official" detection. Apparently, Gill had been overly optimistic.

In the meantime, he had to concede that the original group had done an exemplary job reviewing the remaining chapters and reporting where plagiarism had been found. Their reviews were available to every student on the Google Docs drive; apparently they had not been taken seriously or they were not properly understood at all.

All this left Gill with a dilemma. Although the original group's offenses had been egregious, they had been forced to suffer the consequences without specific warning - unlike the remaining students. Moreover, they had done their best to remedy the situation and had obviously been unaware of the severity of their offense... assuming that they had been honest that they perceived a late submission to be more serious than the risk of plagiarism charges. Was it fair, then, that they should receive the most severe punishment of anyone in the class?

And what should he do about the rest of the class? Roughly one third of the students were associated with plagiarized work in one way or another. Should they all be limited to grades of $\mathrm{C}$ or, given the fact that they had been given fair warning by the original group (through emails and chapter reviews), should they all be failed outright?

Then there was the book itself. Gill had attempted to motivate students by promising that they would participate in a published work. For many, this would be the first time in their academic careers where something they created for class was not discarded once the semester ended. Was abandoning the whole book project fair to those individuals who did not violate the rules?

In less than six hours, Gill would be meeting with his students for the last time in the semester. Grades could not be submitted for another 2 weeks (a consequence of the 12-week term used for graduate courses in Gill's university), but for most of the students, this meeting represented the final meeting of the final class in the program before graduation (at least, it would be if they passed the course). What was he to tell them? 


\section{Exhibit 1: Excerpts from USF Plagiarism Policy}

USF's policy is listed as part of the university's "commitment to the academic honesty and personal integrity of its University community. Academic integrity is grounded in certain fundamental values, which include honesty, respect and fairness." It was drafted by the university's legal counsel and cites State Legislature in support. This policy also includes cheating. These "policies and procedures apply to all students, instructional faculty and staff who participate in administration of academic classes, programs and research at the USF."

\section{(b) Plagiarism}

Definition:

Plagiarism is intentionally or carelessly presenting the work of another as one's own. It includes submitting an assignment purporting to be the student's original work which has wholly or in part been created by another person. It also includes the presentation of the work, ideas, representations, or words of another person without customary and proper acknowledgment of sources. Students must consult with their instructors for clarification in any situation in which the need for documentation is an issue, and will have plagiarized in any situation in which their work is not properly documented.

Clarification:

1. Every direct quotation must be identified by quotation marks or appropriate indentation and must be properly acknowledged by parenthetical citation in the text or in a footnote or endnote.

2. When material from another source is paraphrased or summarized in whole or in part in one's own words, that source must be acknowledged in a footnote or endnote, or by parenthetical citation in the text.

3. Information gained in reading or research that is not common professional knowledge must be acknowledged in a parenthetical citation in the text or in a footnote or endnote.

4. This prohibition includes, but is not limited to, the use of papers, reports, projects, and (d) Multiple Submissions

Definition:

Multiple submissions are the submissions of the same or substantially the same work for credit in two or more courses. Multiple submissions shall include the use of any prior academic effort previously submitted for academic credit at this or a different institution. Multiple submissions shall not include those situations where the prior written approval by the instructor in the current course is given to the student to use a prior academic work or endeavor.

Clarification:

1. Students may not normally submit any academic assignment, work, or endeavor in more than one course for academic credit of any sort. This will apply to submissions of the same or substantially the same work in the same semester or in different semesters.

2. Students may not normally submit the same or substantially the same work in two different classes for academic credit even if the work is being graded on different bases in the separate courses (e.g. graded for research effort and content versus grammar and spelling). 
3. Students may resubmit a prior academic endeavor if there is substantial new work, research, or other appropriate additional effort. The student shall disclose the use of the prior work to the instructor and receive the instructor's permission to use it PRIOR to the submission of the current endeavor.

4. Students may submit the same or substantially the same work in two or more courses with the prior written permission of all faculty involved. Instructors will specify the expected academic effort applicable to their courses and the overall endeavor shall reflect the same or additional academic effort as if separate assignments were submitted in each course. Failure by the student to obtain the written permission of each instructor shall be considered a multiple submission.

\section{(h) Misuse of Intellectual Property}

Definition:

Misuse of Intellectual Property is the illegal use of copyright materials, trademarks, trade secrets or intellectual properties.

Clarification:

Students may not violate state or federal laws concerning the fair use of copies.

\section{Violations and Sanctions for Graduate Students}

The Office of Graduate Studies holds academic integrity in the highest regard. Graduate students are responsible for being aware of and complying with University Regulations and Policies and must conduct themselves accordingly. Sanctions for Academic Dishonesty will depend on the seriousness of the offense and may range from the receipt of:

- An "F" or "Zero" grade on the subject paper, lab report, etc.

- An "F" in the course or activity in which credit may be earned.

- An "FF" in the course (leading to expulsion from the University).

- Academic Dismissal for any violations of academic dishonesty policies or regulations.

- Possible revocation of the degree or Graduate Certificate following a thorough investigation.

Graduate students who are assigned an "FF" grade will be academically dismissed from the University and will not be eligible to apply to any graduate program within the USF system . Procedures regarding Academic Dishonesty and Academic Dismissal may be found on the Office of Graduate Studies' website.

\section{Additional Graduate Guidelines for Academic Dishonesty}

1. If a graduate student who has been accused of academic dishonesty drops the course, the student's registration in the course will be reinstated until the issue is resolved.

2. Any assigned grade may be changed to an "FF", "F", or other grade depending on the instructor's decision or the ultimate resolution of an academic grievance procedure. This includes any instance of academic dishonesty that is not detected until after the student has dropped or completed the course.

3. Notification to the graduate student of the "FF" grade and the option of appeal concerning the alleged academic dishonesty and academic dismissal remains with the instructor and/or department chair (refer to the University Academic Grievance Procedures).

4. Dismissal for reasons of academic dishonesty will be reflected on the student's transcript with the formal notation: Dismissed for Academic Dishonesty. 
5. More serious violations of academic integrity may be referred to the Office of Student Affairs as a student conduct violation.

\section{Appeals}

Once the initial violation of the academic integrity regulation has been documented and fairly discussed by the student and the instructor, the student may appeal the instructor's decision that a violation has occurred. At that point the student will follow the procedures outlined in the USF system's Academic Grievance Procedure Policy. For academic integrity violations that are reviewed at the department and college levels, the respective committees will consider all evidence available to determine if the instructor's decision was correct. The student's ability to proceed within an academic program while an Academic Grievance is in process will be determined by the individual academic program chair/director.

\section{(b) Possible Academic Sanctions and Grading Guidelines:}

Authority of an instructor and the appropriate Chair or Assistant/Associate Dean's office may result in any of the following sanctions:

- Warning to the student

- Voluntary withdrawal by the student from the class(es)

- Temporary exclusion and/or permanent dismissal from the instructor's classroom or academic area, program, or college, pending an expedited appeal.

- Academic sanction, including assignment of a final grade - if the final determination is a dismissal from class, the grade assigned for the class will depend on the student's status at the time of dismissal. If the student had a passing grade in the class at the time of dismissal, a grade of "W" will be assigned for the course. If the student had a failing grade in the class at the time of dismissal, a grade of "F" will be assigned for the course. These grades will become a part of the student's permanent record. In addition, if the academic disruption results in dismissal from more than the classroom or academic area of the incident, this grading policy may be applied in all classes affected. 


\section{Exhibit 2: Debate Activity from the Ism6155 Fall 2013 Syllabus}

\section{Debate Topics}

\#1. Resolved: The need for agility in both software deployment and business processes will ultimately cause large-scale ERP installations to become a rarity.

\#2. Resolved: Within 10 years, economics will drive U.S. companies to contract most of their routine development activities in countries such as India, China and Russia.

\#3. Resolved: Widespread data collection combined with the Internet, compromise an individual's personal privacy to a degree unparalleled in human history.

\#4. Resolved: Within 50 years, we can expect to see information technologies capable of the same type of flexible, common sense reasoning that humans alone are capable of today.

\#5. Resolved: Within the next decade, web-based applications and cloud computing will almost entirely replace the personal (i.e., desktop and laptop) computing.

\#6. Resolved: The open source movement—intentionally or inadvertently—routinely trespasses upon the intellectual property rights of commercial developers of proprietary software.

\#7. Resolved: The current enthusiasm for "big data" is a fad and, in the long run, we will find that its ability to produce better than incremental improvements in organizational performance is overrated.

\section{Debate Protocols}

\section{ROLES}

Active participants in each debate will consist of about $1 / 7$ of the class. There will be two roles:

- Pro: Must support the resolution, as stated

- Con: Must oppose the resolution, as stated

Any student not assigned to a participant role will serve as a discussant, at the end of the debate.

\section{PREPARATION}

The instructor has posted a summary that highlights the key issues that might be considered in the debate. In addition, a presentation by a Debate Briefing team will be made in class a week before the debate. 
The Pro and Con groups are also expected to find their own references that support their positions. These should be included in the Pro and Con wikis on Canvas, along with any notes. Part of the grade assigned to each group will be based on quality/extensiveness of preparation, particularly as indicated in the book chapter section related to the debate position (pro and con).

\section{FORMAT}

The pre-debate preparation will use a Canvas Wiki. The Pro team and the Con team should each prepare their own Wiki page. These pages should consist of a blog of the activities that the group was involved in while preparing for the debate. Because it is a Wiki, everyone in the debate team can contribute from anywhere.

\section{PROCEDURE}

The debate will be conducted over a 50-80-minute block of time, scheduled as follows:

I. Introduction by the moderator (2-5 minutes) Moderator will introduce the topic, using a brief PowerPoint slide show.

II. Presentation of Pro arguments (10-15 minutes): Members of the "Pro" team will present their arguments. PowerPoint slides may be used, if desired.

III. Presentation of Con arguments (10-15 minutes): Members of the "Con" team will present their arguments. PowerPoint slides may be used, if desired.

IV. Questions from the Class, Panel and Instructor (15-30 minutes): Moderator will pose questions to Pro and Con team members. Both sides will have the opportunity to respond to any question, and may also engage in back-and-forth discussions. The instructor and class may also pose questions.

V. $\quad$ Wrap up (5 minutes): Instructor will comment on issues raised during the debate.

At the end of each debate, non-participants will fill out an online evaluation form rating the pro and con debate teams. These will be done on a team basis. In addition, the instructor will evaluate individual contributions to the presentation, so it is important that all team members participate.

Within a week of the actual debate, both the pro and con team will add a section to the draft chapter on the debate. This will count for $50 \%$ of the teams' debate grade (as opposed to individual grades, which are determined separately). 


\section{Exhibit 3: Debate Briefing and Book Activity from the Ism6155 Fall 2013 Syllabus}

\section{OBJECTIVES}

The objectives of the Debate Briefing activity is to provide an unbiased overview of the topics and issues related to each debate. This will allow the debate pro and con teams to focus of presenting arguments based on the facts of the debate, without having to spend most of their time on presenting the facts themselves. There will be two deliverable elements to the briefing:

1. A TEDTalk style presentation on the topic, given one week before the debate itself.

2. A book chapter on the topic. In addition to the briefing itself, the Pro and Con teams will add sections presenting their own arguments to the end of the chapter.

The collection of debate briefings will be assembled into a book, which should be printed by the end of the semester (i.e., in December). In the event the chapters prepared by the class are of sufficient quality, The Informing Science Press, an academic publisher, has expressed a willingness to publish the book and list it on its website.

\section{ORGANIZATION}

Two teams of 3-4 students will be assigned to each briefing activity. Each team will have its own responsibility:

1. Presentation Team: Will present a Debate Briefing presentation-related to the following week's debate - at the end of class. These briefings will take the form of a TEDtalk - they should be informative, engaging, and should last NO MORE THAN 18 minutes. In addition, the team will act the principal peer reviewers for the presentation chapter. At the end of class, students who were not on the teams will evaluate the presentations using an online form. These will be done on a team basis. In addition, the instructor will evaluate individual contributions to the presentation, so it is important that all team members participate.

2. Chapter Team: Will write the majority of a book chapter on the debate topic. The first draft must be submitted no later than the day of the debate. It should use the Google Docs template supplied. The team will then be responsible for editing and improving the chapter in response to subsequent reviews by peers (and the instructor). They will also act as principal reviewers for the debate portions added to the end of each chapter by the debate teams. At the end of the semester, the chapter grades will be assigned by the instructor.

Students may not sign up for the number debate briefing presentation/chapter and debate topic (i.e., the same number for both).

\section{LOGISTICS}

A separate shared folder on Google Docs will be established for each debate, under a top level folder for the class. That folder will contain: 
1. Chapter draft. It will start out as a template and participants - particularly the chapter team-will edit it and transform it into a book chapter. It is critical that formatting - both of text and references - be maintained and reviewers will be responsible for maintaining that consistency. (A clean "master template" will be placed at the top level folder for the class, in case a chapter becomes too badly mangled...)

2. References: References-formatted according to APA formatting guidelines-should be maintained in a separate document which should be kept current. It is critical that references match what is used in the chapters precisely, since that could be a barrier to publishing the book.

3. Debate slides: When the Debate Teams (Pro and Con) and Debate Briefing Team completes their presentation, they must upload a copy of their slides to the corresponding debate folder.

4. Resources: A subfolder called "Resources" will be created under the debate folder. PDF files of articles and other notes can be uploaded here. Please do not upload large videos here, since they could cause me to run out of space on my Google drive.

\section{REVIEWING}

Reviews will be conducted using Expertiza. This is an open source project developed by North Carolina State University (NCSU) that is designed for student peer review. Each student's review will involve three elements:

1. The draft of the chapter should be pasted into an MS-Word document and track changes should be used to make detailed comments on the chapter.

2. Three general questions, provided in the rubric form, should be answered. These involve identifying the key strengths/weaknesses of the chapter and making specific suggestions for improvement.

3. A thorough reference check, ensuring that references are included and properly cited. The team may collaborate on this part of the review - since it is more objective - in which case team members should each paste a copy of the same values and comments into the Expertiza form provided.

\section{ASSESSMENT}

If this project is going to be successful, each of you must carefully review the chapters assigned to you, and substantial weight in final grades will be allocated to your individual review efforts. Review assignments (and credit) will be allocated as follows:

- Briefing Presentation Team: Assigned as principal reviewer of the initial chapter draft. 50\% of grade allocated to presentation quality, $50 \%$ to review quality.

- Chapter Team: Assigned as principal reviewer of final chapter draft-ensuring proper formatting, references, and polishing the debate sections at the end of the chapter. $50 \%$ of the grade allocated to chapter quality, $50 \%$ to review quality. 


\section{Exhibit 4: Screen Capture of Google Docs Site}

\begin{tabular}{|c|c|c|}
\hline TITLE & OWNER $\rightarrow$ & LAST MC \\
\hline$\square$ 的 Debate1 Shared & me & Nov 14 \\
\hline$\square$ it Debate2 Shared & me & Nov 14 \\
\hline$\square$ h $\square$ Debate3 Shared & me & Nov 14 \\
\hline$\square$ is Debate4 Shared & me & Nov 14 \\
\hline$\square$ h th Debate5 shared & me & Nov 14 \\
\hline$\square$ it 19 Debate6 Shared & me & Nov 14 \\
\hline$\square$ iो 19 Debate7 shared & me & Nov 14 \\
\hline$\square$ iो Pro and Con Review-Backup Shared & me & Nov 14 \\
\hline$\square$ it 19 Review-Backup Shared & me & Nov 14 \\
\hline$\square$ तो Turnltin Reports Shared & me & Nov 14 \\
\hline$\square$ 하 $\equiv$ Master Chapter Template Shared & me & Nov 14 \\
\hline$\square$ it $\equiv$ Master References Shared & me & Aug 24 \\
\hline$\square$ 站 $\equiv$ Master Review Template Shared & me & $12: 21 p$ \\
\hline$\square$ 站 Pro and Con Review Template Shared & me & $12: 20 p$ \\
\hline
\end{tabular}




\section{Exhibit 5: Excerpts from the Master Chapter Template}

\section{Introduction}

The resolution to be discussed in this chapter is:

The resolution here:

\section{Overview}

The briefing chapter should always begin with an introduction section. This section should provide a brief overview of the topic and then list important questions that need to be addressed in the chapter. The "Introduction" heading should be in the Heading 1 style, centered. The "Overview" and "Question" headings should be in the Heading 2 style.

Typically, I would expect the Overview to be around a page, and somewhere around 5-10 questions. These may include some of those that were included on Canvas, but you should not feel limited by those questions.

\section{Questions}

Questions to be addressed in the chapter should be presented as a bullet point list, such as the following:

- What writing style should be employed?

- How do I handle references?

- How do I handle tables?

- How do I handle figures and other graphics?

The list of questions should parallel the remaining sections of the chapter (aside from the Pro and Con sections at the end). In some cases, you may decide to address a question as a subheading (Heading 2) within a broader heading (Heading 1). As an example, as I did for the "Tables" and "Figures and Other Graphics" section.

\section{Writing Styles}

Given that the goal of the project is to produce a publishable work, it is best to be as consistent as possible across chapters. For that reason, we will use Arial for all chapters and will use the basic heading styles (Heading 1, Heading 2 and Heading 3). Do not worry about pagination, as I will have to move the material into a standard book format (e.g., $6 \mathrm{x}$ 9) and will therefore need to make adjustments to the final manuscript if we go ahead and print it.

Generally speaking, writing should be in the past tense--so it doesn't seem dated a few years from now. When it seems more natural, you may use the first person plural ("we"). One of the best pieces of writing advice that I ever received was to try to keep sentences short. For this type of writing, I would suggest that average sentence length be kept below 15 words. Whenever a sentence exceeds 20 words, think about how it might be broken up. 
Overall, your chapter should read like a narrative--not like an outline. You can, however, use bulleted lists or tables where appropriate.

In terms of chapter length, you should probably shoot for 20-25 pages for the main section and about 5 pages for each debate team (10 pages total). If you vary by more than $30 \%$ from these sizes, if may make the chapters inconsistent. A bit of inconsistency, however, can be tolerated if you feel it is necessary to make your points.

If main level (Heading 1) sections get too long, break them into shorter (Heading 2) sections. You may even choose to go one level deeper (Heading 3 ) if needed. When subsections are too short, however, the work can seem a bit choppy to the reader.

\section{References}

When preparing your chapter, keep all references in a separate references document. Not only will this save you a lot of going back and forth when you are writing and referencing works in your chapter, it will also make it easier when assembling the final book.

\section{Basic Format}

We need to be very consistent in citing works. For this reason, we will use the APA standard for references. In the text, we always refer to references in parentheses. For example, if I wanted to reference an article that I published in 2009, it would appear as (Gill, 2009). When you want to reference multiple articles, separate them with semicolons (e.g., Gill, 2009; Doe, 2011). Table 1 contains examples of common types of references:

Table 1: Common APA Reference Types

\begin{tabular}{|l|l|}
\hline Article & $\begin{array}{l}\text { Author-Last-Names, Initials. (Year). Title of article: Only the first letter of the } \\
\text { title and proper nouns are upper case. Journal name in italics, Vol(number). } \\
\text { Page\#-Page\#. }\end{array}$ \\
\hline Book & $\begin{array}{l}\text { Author-Last-Names, Initials. (Year). Title of book in italics: Only the first letter } \\
\text { of the title and proper nouns are upper case. Publisher City: Publisher Name. }\end{array}$ \\
\hline $\begin{array}{l}\text { Chapter in } \\
\text { Book }\end{array}$ & $\begin{array}{l}\text { Author-Last-Names, Initials. (Year). Title of chapter: Only the first letter of the } \\
\text { title and proper nouns are upper case. In Editor-Last-Names, Initials. (Year). } \\
\text { Title of book in italics: Only the first letter of the title and proper nouns are } \\
\text { upper case. Publisher City: Publisher Name. Page\#-Page\#. }\end{array}$ \\
\hline $\begin{array}{l}\text { Web } \\
\text { Reference }\end{array}$ & $\begin{array}{l}\text { Author-Last-Names, Initials. (Year). Title of page: Only the first letter of the } \\
\text { title and proper nouns are upper case. Retrieved mm/dd/yyyy from url. }\end{array}$ \\
\hline
\end{tabular}




\section{Exhibit 6: Excerpts from Master Review Template}

\section{Chapter Review}

Debate number:

Your name:

Date of most recent review:

What are the greatest strengths of the chapter?

Date of most recent update:

$<<$ Add your text here. Always put the most recent text on top, and separate it from earlier versions by inserting a horizontal line>>

What are the greatest areas for improvement for the chapter?

Date of most recent update:

$<<$ Add your text here. Always put the most recent text on top, and separate it from earlier versions by inserting a horizontal line $>>$

What are your specific suggestions for improving the chapter?

Date of most recent update:

$<<$ Add your text here. Always put the most recent text on top, and separate it from earlier versions by inserting a horizontal line>> 


\section{Exhibit 7: Email to Department Chair (edited to remove identifying information)}

[Chair name]:

In going over the chapter drafts for the capstone book project, my graduate assistant discovered that a substantial fraction of one of the chapters was copied directly from an article without any type of attribution. This is REALLY serious for this particular project, since the intent was to actually publish the book, and doing so with blatant plagiarism would have been an unmitigated disaster. I made this abundantly clear to students throughout the course.

I just sent [each student involved] the following email:

There is a serious--potentially graduation-threatening--problem with the Chapter 2 write-up. Since you are the team assigned to the chapter draft, I think we had better meet in person as soon as possible. Please email me with your availability.

If this is the first incident of this type for the person or persons involved, my intention is to provide $\mathrm{him} / \mathrm{her} /$ them with a path to redemption (in the form of a $\mathrm{C}$ or, if extreme contrition is demonstrated, perhaps a B), albeit a difficult one. This would involve 3 steps: 1) rewriting the section, 2) checking all the other chapters for plagiarism, and 3) sending an email to all the remaining students in the course explaining what happened and apologizing.

What I request is that you join me in meeting with the students, assuming we can find a time in your schedule that is available. My hope is that one of them will cop to the problem so we do not have that issue of determining which one. But I believe this is not a problem that should be swept under the rug, and hope that you feel the same.

//Gill Signature// 


\section{Exhibit 8: Email from Chapter Authors to Classmates (edited to remove identifying information)}

Hi Friends,

This is //chapter// Author team reporting a mistake we did due to misunderstanding Professor Dr. Gill's requirement on writing the chapter. The submission which we did initially was only a Rough draft (Framework) of the topic Off-shoring which contained copy pasted text from other referenced materials which we intended to modify based on our understanding before our final submission. But Dr. Gill is expecting that it should consist of the students' own words, with properly cited references, and where appropriate occasional blocks of text that are clearly identified as being direct quotes from other sources (and were properly cited) prior to putting it out for review. Since we submitted a rough draft with other unreferenced material for review, we feel extremely sorry for wasting the time of reviewers. If you all could review the content which we submitted on Tuesday in //chapter// it would be of great help.

Also we would like to inform Authors of other chapter that there has to be no content just copied from external sources without proper referencing. Since Dr. Gill is in a plan to publish all the chapters compiled as a book the content has to be in such a way that it should avoid all types of plagiarism issues. Dr. Gill is also planning to enable a Turntin verification assignment for all chapters 


\section{References}

Korn, M. (2013). India fuels surge in foreign students. Wall Street Journal, 11/5/2013.

Lavelle, L., \& Duermeijer, C. (2013). Understanding and addressing research misconduct. Editors Update, 40. 17 September 2013. Retrieved from http://editorsupdate.elsevier.com/issue-40-september-2013/understanding-andaddressing-research-misconduct

Nabi, S. (2012). 7 anti-plagiarism services for stopping cheaters. Education Dive. Retrieved from http://www.educationdive.com/news/7-online-anti-plagiarism-services/48202/

Plagiarize. (2013). In Merriam Webster's Online Dictionary. Retrieved from http://www.merriamwebster.com/dictionary/plagiarize

SV-POW Blog. (2013). Plagiarism is nothing to do with copyright. September 20, 2013. Retrieved from http://svpow.com/2013/09/20/plagiarism-is-nothing-to-do-with-copyright/

US Copyright Office. (n.d.). Definitions. Retrieved from http://www.copyright.gov/help/faq/faq-definitions.html

US Patent \& Trademark Office. (n.d.). Trademark, patent, or copyright? Retrieved from http://www.uspto.gov/trademarks/basics/definitions.jsp

USF Library. (2013). Avoiding plagiarism. Retrieved from http://www.lib.usf.edu/guides/avoiding-plagiarism/

\section{Biographies}

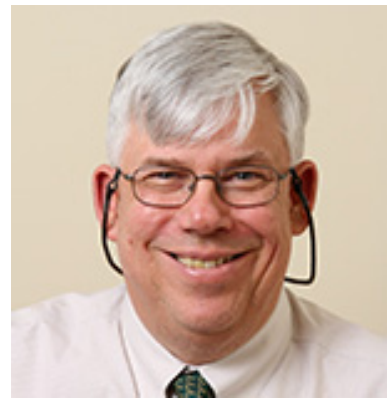

Grandon Gill is a Professor in the Information Systems and Decision Sciences department at the University of South Florida. He holds a doctorate in Management Information Systems from Harvard Business School, where he also received his M.B.A. His principal research areas are the impacts of complexity on decision-making and IS education, and he has published many articles describing how technologies and innovative pedagogies can be combined to increase the effectiveness of teaching across a broad range of IS topics. Currently, he is Editor-inChief of Informing Science: The International Journal of an Emerging Transdiscipline and an Editor of the Journal of IT Education.

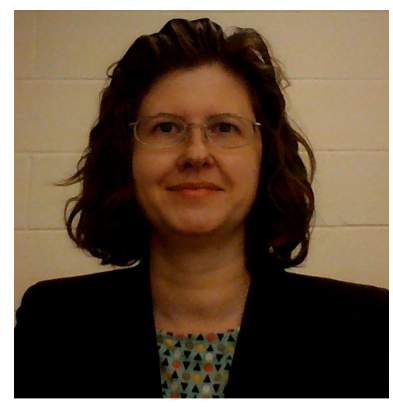

Amy Connolly is a fifth-year doctoral student and instructor in the Information Systems and Decision Sciences department at the University of South Florida, where she also received her MS and BS in Management Information Systems. Her principal research area is the impact of social media on volunteers. Currently, she is preparing to defend her dissertation in Spring 2014 and looking forward to an academic career in the Informatics Department at University of South Carolina Upstate. 